\title{
Risk Anomaly: A Review of Literature
}

\author{
Dr. Mayank Joshipura \\ Professor and Head of the Department Finance at School of Business Management \\ NMIMS University, Mumbai, India \\ E-mail: mayank.joshipura@nmims.edu
}

Mrs. Nehal Joshipura

Assistant Professor (Finance), Durgadevi Saraf Institute of Management Studies

Mumbai, India

E-mail: nehal.joshipura@dsims.org.in

Received: Sep. 4, 2015 Accepted: Oct. 13, 2015 Published: December 1, 2015

doi:10.5296/ajfa.v7i2.8262 URL: http://dx.doi.org/10.5296/ajfa.v7i2.8262

\begin{abstract}
Number of studies show that portfolio of low risk stocks outperforms portfolio of high risk stocks as well as the market portfolio over the full market cycle on risk adjusted basis and in some cases, absolute basis as well. This surprising contradiction to classic finance theory led by CAPM has held its ground over long periods of time, across different markets and different methodological choices. This review paper aims at contributing to the body of knowledge in four ways. One, it highlights and links different strands of literature on low risk anomaly that has evolved over a period of time. Second, it highlights, different methodological choices that have been used. Third, it classifies explanations for persistence of risk anomaly into economic and behavioral explanations and explanations that try to explain the anomaly away. Fourth, it reviews the state of current research and explores potential but yet underexplored areas of research on risk anomaly.
\end{abstract}

Keywords: Market efficiency, risk anomaly, CAPM, Preference for lottery, limits of arbitrage, volatility effect 


\section{Introduction}

Finance theory suggests that there is clear and linear positive relationship between the risk and the return. One needs to assume higher risk in order to earn higher return. Modern Portfolio theory (Markowitz, 1952) offers the framework to optimize risk return trade-off based on investors' risk budget by allowing them to construct a portfolio that offers the highest level of expected return at the given level of volatility or alternatively allows to construct a portfolio that offers the higher expected return at given level of volatility. Capital Asset Pricing Model (CAPM) (Sharpe, 1964) argues that while there is a positive relation between the risk and return, the reward for the additional risk is limited to the systematic risk only and not available on the total risk. The logic is that a rational investor should be able to diversify away the unsystematic risk and hence no risk premium should be associated with such risk. However, when it comes to measuring performance of any managed portfolio, the most popular measure is the Sharpe ratio that measures the excess return (return of a portfolio over risk free return) to volatility, measured by standard deviation and not beta. The reason why an actively managed portfolio may not be a fully diversified is that it intends to outperform the benchmark market portfolio (A proxy for fully diversified portfolio with zero unsystematic risk) on a risk-adjusted basis. Therefore they may retain unsystematic risk for the superior returns. In such cases, investors need reward not only for the systematic risk of the portfolio but for the unsystematic risk retained in the portfolio as well.

However, empirical evidence showcasing superior risk adjusted performance of Low Volatility (LV) and Minimum Variance (MV) investment strategies compared to benchmark as well as high risk have raised questions about direction and degree of positive risk return relationship preached by classic finance theory. A large body of overlooked academic research reveals that risk and return within the equity markets are not correlated, or if they are, it is negative correlation. This surprising contradiction seems to be true and persisting and not varying a great deal with difference in methodological choices and markets. More recently, there are several studies that have highlighted that risk and expected return relationship is not only flat but also actually negative within the asset class such as equity if not across the asset class. This is known as "low risk anomaly". The proposition is that "portfolio consisting of low risk stocks not only outperforms its high volatility counterpart but also market capitalization weighted benchmark portfolio over a period of full market cycle".

Now the next question that immediately comes to mind is that is it possible to have portfolios, which give returns greater than High Volatility (HV) portfolio and market portfolio with lesser risk? Is it possible to have a portfolio, which lies above the Capital market Line? This is the basic premise behind 'exploring for risk anomaly in stock markets!'

There are two ways to test and exploit risk anomaly - [a] Low volatility (LV) portfolio and [b] Minimum variance (MV) portfolio. Many studies in developed markets report superior returns associated with low volatility portfolios over the market portfolio as well as the portfolios with higher risk. The risk being measured either by standard deviation of returns or by beta of the stock returns.

Here is the brief explanation of the LV and MV investment strategies - 
(a) Low Volatility investing - This strategy sorts or ranks all the stocks by their historical volatility and/or beta and then forms a portfolio using subset of these stocks - comprising those with the lowest beta and/or volatility.

(b) Minimum Variance investing - It relies on observations and/or estimates of correlations of individual stocks. Individual stocks have higher risk, but a well-diversified portfolio when optimized for minimum risk is identified as the Minimum Variance Portfolio.

These investment strategies have been noteworthy in the sense that they have been able to deliver higher absolute returns as well as risk-adjusted returns over time. Both MV and LV portfolios reduce volatility and face least drawdowns ${ }^{1}$.

We organize remaining part of this paper as follows. Section 2 discusses review of literature in general, Section 3 discusses different methodological choices, Section 4 discusses possible explanations and Section 5 discusses Road ahead followed by Section 6 conclusion.

\section{Review of Major Literature}

Initial evidence on "Betting against beta" version of risk anomaly throwing light on flatter than expected or even inverse relationship between risk and return as predicted by CAPM (Sharpe, 1964) traces back to 1970's where ((Black, 1972),(Haugen \& Heins, 1975)) show flatter than expected and negative relationship between beta and expected returns. Further (Fama \& French, 1992) report flat relationship between beta and cross section of returns in U.S. markets for 1963-1990 period. (Haugen \& Baker, 1991) and (Haugen \& Baker, 1996) offer initial evidence on inverse relationship between risk and return.

More recent studies on risk anomaly can be classified based on choice of

1) portfolio construction method- minimum variance vs. volatility sorting

2) choice of risk measures- standard deviation, beta, idiosyncratic risk

3) choice of portfolio construction and holding period-short vs. long

We further classify various studies based on the way they attempt to explain or explain away, the risk anomaly.

1) Studies attempting to explain the volatility effect either by economic reasoning or by behavioral explanation

2) Studies attempting to explain away the risk anomaly.

Minimum variance investing or low volatility investing has been inspired by early work from Haugen and Baker (Haugen \& Baker, 1991) ${ }^{2}$. For the period covering the years 1972 to 1989 , the authors report that repeatedly investing into a stock portfolio constructed to expose

\footnotetext{
${ }^{1}$ Drawdown is defined as peak to trough decline during a specific period in the stock price.

${ }^{2}$ Acadian Asset Management, AXA Rosenberg, Analytic Investors LLC, Invesco, LGT Capital Management, MSCI Barra, Robeco, SEI, State Street Global Advisors, Martingale Asset Management LLC and Unigestion are running minimum variance index concepts. Ishare \& Russel have already launched ETFs based on MV indices.
} 
investors to minimum risk (as measured by variance) would outperform the Wilshire 5000 index (provide a higher Sharpe ratio ${ }^{3}$ ). Today, the body of research supporting the low risk anomaly studies the period from 1926 to the present.

Many other studies specific to U.S. markets including (Chan, Karceski, \& Lakonishok, 1999), (Schawartz, 2000), (Jagannathan \& Ma, 2003) report both higher returns and lower realized risks for the minimum variance portfolio (MVP) versus a capitalization-weighted benchmark (MWP).

We discuss some of the major studies and their propositions below.

Clarke et al. (Clarke, DeSilva, \& Thorley, 2006a) study focus on the characteristics of minimum-variance (MV) portfolios. The study reports that MV portfolios based on the 1,000 largest U.S. stocks over the period of $1968-2005$, achieved a volatility reduction of about $25 \%$ while delivering comparable or even higher average returns than the market portfolio. This means that the MV portfolios had around $75 \%$ of the risk of the market portfolio, with returns comparable to those of the broad market. MV portfolios gave average $6.5 \%$ excess return above T-Bills with a volatility of $11.7 \%$ whereas the market index gave average excess return of $5.6 \%$ with a volatility of $15.4 \%$.

Blitz \& Vliet (Blitz \& Vliet, 2007) report that low volatility stocks have superior risk-adjusted returns relative to the FTSE World Development Index. The study also reports that low beta stocks have higher returns and high beta stocks have lower returns than predicted by CAPM. They also provide detailed analysis of the volatility anomaly and demonstrated its robustness across regions and to controls for size, value and momentum effects. They show outperformance associated with low historical volatility stocks both in terms of higher Sharpe ratio and higher positive CAPM alpha. They attribute such sustainable outperformance to restricted borrowing as reported by (Black, 1972), decentralized investment approach and behavioral biases such as preference for lotteries. Further details on explanations are given in possible explanations section of this document.

Ang et.al. ((Ang, Hodrick, Xing, \& Zhang), 2006, 2009) report evidence for inverted relationship between idiosyncratic volatility as opposed to systematic and total risk for a very short term-one month volatility measure in U.S. as well as other global markets.

In another recent study by (Baker \& Haugen, 2012) finds that from 1990 - 2011, low risk stocks have produced higher returns in every market worldwide - including emerging markets.

Frazzini \& Pedersen (Frazzini \& Pedersen, 2010) document that low-risk securities have high risk-adjusted returns in global stock, treasury, credit and futures market.

Most recently, (Frazzini \& Pedersen, 2014) report evidence for betting against beta and attributed to leverage constrained investors seeking superior returns bid up the high beta stocks that in turn results into lower expected returns on high beta stocks.

\footnotetext{
${ }^{3}$ Sharpe Ratio $=$ Excess return on portfolio over risk free rare divided by standard deviation of portfolio returns.
} 
Choueifaty \& Conignard (Choueifaty \& Coignard, 2008) argue that maximizing a diversification ratio, the weighted average of the stocks' volatilities divided by the portfolio volatility, as an approach to achieve risk-adjusted returns is superior to those of the market cap-weighted portfolios. Based on the results on the universe of U.S. and Eurozone securities, they conclude that, if all of the stocks in the study's universe possess the same volatility, then the maximum diversification portfolio is equal to the global minimum-variance portfolio.

Baker et. al. (Baker, Bradley, \& Wurgler, 2011) report that contrary to basic finance principles, high-beta and high-volatility stocks long underperformed low-beta and low-volatility stocks.

Karceski (Karceski, 2002) provides behavioral explanation to low risk anomaly. According to him, mutual funds investors tend to chase returns over the time and across the funds, possibly because of an extrapolation bias. These forces make fund managers care more about outperforming in bull markets rather than underperforming in bear markets and therefore increase their demand for high beta stocks and reduce required rate of returns.

Baker et. al. (Baker, Bradley, \& Wurgler, 2011) \& (Baker, Bradley, \& Taliaferro, 2013) provide some explanation for the presence and sustainability of low risk anomaly. According to them, the typical institutional investor's mandate to outperform a fixed benchmark discourages arbitrage activity in high-alpha, low-beta stocks and low-alpha, high-beta stocks. They replicate (Pettengill, Sundaram, \& Mathur, 1995) study which reports higher (lower) total return associated with high beta stock in months where market report above (below) median return compared to their low beta counterparts. The results are similar. However, on CAPM adjusted basis, low beta stocks still outperform in bull as well as bear markets and provide evidence for presence of low risk anomaly over market cycles.

Soe (Soe, 2012) tests the low-risk anomaly in different markets and across various market cap stocks to find that the low-volatility effect is not unique to the U.S. equity markets; it is present on a global scale.

Carvalho et. al. (Carvalho, Raul, Xiao, \& Pierre, 2012) find that a rankings-based or quintile-based low volatility construction approach could be considered as an equal risk budget strategy that does not account for the impact of correlations between stocks.

While evidence for risk anomaly is growing, some recent studies report findings in favor of classic positive risk-return relationship or dispute the methodological choices of other studies reporting flat or inverted risk-return relationship.

Martellini (Martellini, 2008) finds that positive relationship between risk and return is intact. However, one must note that the study uses only surviving stocks and therefore systematically ignores stocks delivering significant negative returns before disappearing. (Fu, 2009) claims that one should focus on expected rather than historical volatility, and reports a positive relation between risk and return by using EGARCH models to estimate idiosyncratic volatility.

\section{Methodological Choices}


Following variations in term of methodological choices are popular to test presence of risk anomaly.

- Minimum variance vs. simple volatility sorting based approach

- Choice of measure of risk- historical standard deviation, beta or idiosyncratic risk

- Choice of return measures-simple vs. compounded

- Choice of period for volatility estimation- short vs. long

- Choice of universe- developed countries vs. emerging markets, size and liquidity of the stocks

- Weighing scheme: Equally weighted vs. value weighted

- Division of portfolios-Decile vs. quintiles

Given below are some of the examples of different methodological choices used in some of the important studies. (Clarke, DeSilva, \& Thorley, 2006a), (Chan, Karceski, \& Lakonishok, 1999), (Schawartz, 2000), (Jagannathan \& Ma, 2003) use minimum variance based approach whereas (Blitz \& Vliet, 2007), (Ang, Hodrick, Xing, \& Zhang, 2006), (Baker \& Haugen, 2012), (Frazzini \& Pedersen, 2014) use risk measure based sorting approach.

(Clarke, DeSilva, \& Thorley, 2006a), (Bali \& Cakici, 2008), (Baker, Bradley, \& Wurgler, 2011) use standard deviation or variance as risk measure, (Frazzini \& Pedersen, 2014) use beta as risk measure. (Blitz \& Vliet, 2007) use both standard deviation as well as beta as risk measure. (Ang, Hodrick, Xing, \& Xhang, 2009) use idiosyncratic volatility as risk measure. (Fu, 2009) uses volatility using EGARCH rather than historical volatility.

(Ang, Hodrick, Xing, \& Zhang, 2006), (Martellini, 2008), (Bali \& Cakici, 2008) use simple returns, whereas (Blitz \& Vliet, 2007), (Baker, Bradley, \& Wurgler, 2011) use compounded returns.

(Blitz \& Vliet, 2007) use three year volatility of weekly returns, (Baker, Bradley, \& Wurgler, 2011) use five year volatility of monthly returns. On extremes, (Martellini, 2008) use ten-year volatility of monthly returns, whereas, (Ang, Hodrick, Xing, \& Xhang, 2009) and (Bali \& Cakici, 2008) use very short term one month volatility of daily returns. (Fu, 2009) does not use historical volatility at all and uses EGARCH estimate of daily returns volatility.

Most of the studies focus on U.S. markets using CRSP data including (Clarke, DeSilva, \& Thorley, 2006b), (Ang, Hodrick, Xing, \& Zhang, 2006), (Fu, 2009), (Baker, Bradley, \& Wurgler, 2011). However, there are number of studies focusing on data from other regions and emerging markets and specific size and liquidity based screen in choice of their universe. (Blitz \& Vliet, 2007) use FTSE world stocks sample with focus on large stocks with regional focus on Japan and Europe data, besides U.S. (Baker, Bradley, \& Wurgler, 2011) use CRSP top 1000 sample besides all CRSP stocks in their study. (Ang, Hodrick, Xing, \& Xhang, 2009) use MSCI Europe and Asia sample in their study. (Blitz, Pang, \& Vliet, 2012) focus on 
universe from emerging markets only. (Martellini, 2008)chooses universe with only survivor stocks form CRSP during entire period of 1975 to 2004.

(Blitz \& Vliet, 2007), (Fu, 2009) use decile portfolios, (Ang, Hodrick, Xing, \& Zhang, 2006), (Ang, Hodrick, Xing, \& Xhang, 2009), (Bali \& Cakici, 2008), (Martellini, 2008), (Baker, Bradley, \& Wurgler, 2011), (Blitz, Pang, \& Vliet, 2012) use quintile portfolios.

While (Blitz \& Vliet, 2007), (Martellini, 2008), (Baker, Bradley, \& Wurgler, 2011) use equal weighing scheme, (Ang, Hodrick, Xing, \& Zhang, 2006), (Ang, Hodrick, Xing, \& Xhang, 2009), (Bali \& Cakici, 2008) use value weighing scheme and (Fu, 2009) uses both.

\section{Possible Explanations}

While it is difficult to explain presence of such low risk anomaly and its persistence using traditional finance theory and models such as capital asset pricing model (CAPM) and Markowitz modern portfolio theory (MPT), there are some plausible explanations to explain such consistent outperformance of low volatility investment strategies. As we report earlier, there are two sets of explanations available. One set of explanations tries to explain evidence of low risk anomaly using economic or behavioral reasoning. Whereas the other set of explanations tries to explain it away.

\subsection{Economic explanations}

Following are some of the economic explanations.

1. Borrowing restrictions: Leverage is essential to take full advantage of attractive absolute returns of low-risk stocks. However, in practice there are several restrictions on short selling and leverage allowed for investment purpose. (Black, 1972) documents borrowing restrictions applicable for both the individual as well as most of the institutional investors. Black (Black, 1993) argues that one should look at asset allocation between bonds and low risk equity rather that bond and market portfolio of equity. However, for that, one has to recognize low risk equity as a separate asset class.(Blitz \& Vliet, 2007) and (Baker, Bradley, \& Wurgler, 2011) explain underpricing of low volatility stocks and overpricing of high volatility stocks due to such borrowing restrictions.

2. Limits of arbitrage: (Baker, Bradley, \& Wurgler, 2011) attribute low-beta high-alpha and high-beta low-alpha scenario to the fact that most of the institutional investors are working for beating some benchmark and in order to achieve that they tend to go for high beta stocks. This is because chasing high beta stocks is an easier way to beat the benchmark rather than search for stock with alpha that is high enough to enable them to outperform the benchmark. The alternative way of doing it is by investing in low beta stocks using leverage and outperforming benchmark and benefiting from alpha as well. However, restrictions on borrowing including 'long only' mandate leads to elimination of possibility of exploiting arbitrage opportunity between low beta-high alpha and high beta-low alpha stock.

3. Decentralized investment approach: In professional investment industry, the practice is that the chief investment officer makes the asset allocation decision and in second stage, capital is allocated to managers who buy securities within the different assets classes. Binsbergen et al. 
(Binsbergen, Brandt, \& Koijen, 2008) attribute inefficiencies in decentralized investment management approach to profit maximizing asset managers' search for outperformance in up market rather than in the down market.

4. Short selling constraints: (Hong \& Sraer, 2012) show that high-risk stocks have greater divergence of opinion about their payoffs making them more prone to speculative overpricing than low-risk ones. Short selling constraints, does not allow arbitrageurs to correct the inflated prices of high volatility stocks immediately by going long on ignored low risk stocks and shorting high risk stocks, which in turn, leads to underperformance of high volatility stocks.

5. Agents maximize option value: (Baker \& Haugen, 2012) observe that portfolio managers are typically paid a base salary and sufficiently high bonus based on the portfolio return. This makes their compensation resembling a call option with payoff function: $c+\max (R p-X, 0)$, where $\mathrm{Rp}$ is portfolio return, $\mathrm{c}$ is base salary or fee and $\mathrm{X}$ is the hurdle rate. This in turn results in portfolio managers seeking higher risk and focusing on outperformance during up market rather than down market and taking higher risk by tilting portfolios towards high beta stocks.

\subsection{Explanations based on investor's behavior and biases}

There is the other set of explanations highlighting irrational behavior of not fully diversified investors and how behavioral biases influence investment decision and make investor prefer high volatility stocks with positive skewness and lottery like payoffs and thereby pushing them in to overpriced territory.

1. Preference for lottery: The general assumption is that investors are risk averse and that is true under normal circumstances. A layman tends to reject a bet with 50 percent probability of winning Rs. 110 and 50 percent probability of losing Rs.100 despite positive expected payoff associated with this bet. (Kahneman \& Tversky, 1979) explain such behavior as "loss aversion". However something strange happens with individuals when probability shifts. If the same individual who rejected the bet with positive expected payoff of Rs.5 earlier is now offered a bet with almost certain loss of Re. 1 and a small chance (probability is 0.15 percent) of getting Rs.5000, is willing to accept the bet despite negative expected payoff associated with it. That's the very reason, people buy lottery! This has something to do with positive skewness of payoffs and not volatility. However, (Mitton \& Vorkink, 2007) highlighted that high volatility individual stocks with limited liability, are also positively skewed. Buying a high volatility, low priced stock is like buying a lottery - high probability of losing money vs. a small chance of doubling or tripling money in short term. (Kumar, 2009) shows that individual investors show clear preference for stocks with lottery like payoff measured as idiosyncratic volatility or skewness. (Boyer, Mitton, \& Vorkink, 2010) argue that volatility is a proxy for expected skewness.

2. Mental Accounting: (Blitz \& Vliet, 2007) give a related mental-accounting explanation for the volatility effect, arguing that investors may make rational risk-averse choices for asset allocation decision, but when it comes to security selection within the asset class, they become risk seeking or risk neutral and show preference for high volatility investments with lottery like payoffs. 
3. Preference for attention-grabbing stocks: (Falkenstein, 1996) documents that mutual funds hold firms-in-news more. (Barber \& Odean, 2008) also find that individual investors are net buyers of attention-grabbing stocks. Boring low-volatility stocks are neglected causing the volatility effect.

4. Representativeness Bias: (Falkenstein, 2009) argues that representativeness bias may also explain the volatility effect. As explained by (Kahneman \& Tversky, 1983), representativeness bias is that people rely more on appealing anecdotes than on dull analysis. So it creates a logical error: stocks that had the highest returns were risky, therefore risky stocks should have higher expected returns. The widespread heuristic that 'risk creates returns premium' causes investors to overweight risky stocks to generate return premium. This actually negates the effect through their collective action.

5. Overconfidence: People generally see themselves as better than average on nearly any subjective and socially desirable dimension. (Falkenstein, 2009) argues that many people believe that they are capable of successful stock picking. Thus investors may be biased towards high-risk stocks for so-called alpha discovery purposes, rooted in overconfidence. Also with regard to market timing, there is an implication leading to risk anomaly. If an investor is confident about market rising, he will surely park his money into high-beta stocks to benefit most. If he senses that the market will go down, he will not invest into low-beta stocks; rather will stay away from the equities.

\subsection{Explanations trying to explain it away}

There are many studies that try to explain away risk anomaly based on arguments related to methodological choices and other known investment effects. Following studies offer such findings.

(Bali \& Cakici, 2008) argue that the negative expected returns associated with high volatility stocks reported by (Ang, Hodrick, Xing, \& Zhang, 2006) are due to presence of small and illiquid stocks with lottery like payoffs. Removing these stocks form the sample makes the anomaly insignificant. (Martellini, 2008) finds that positive relationship between risk and return is intact using long term volatility rather than short term. However, one must note that the study uses only surviving stocks and therefore systematically ignores stocks delivering significant negative returns before disappearing. (Fu, 2009) claims that one should focus on expected rather than historical volatility, and reports a positive relation between risk and return by using EGARCH models to estimate idiosyncratic volatility. (Scherer, 2011) argues that large part of excess return of minimum variance portfolio over benchmark portfolio is attributable to systematic exposure to size and value factors and volatility effect in large part a mere proxy for value effect. (Poullaouec, 2010) shows that while MSCI MV index has outperformed MSCI World index by $0.5 \%$ per annum over a period of 1988 to 2010, large chunk of this outperformance comes from a period of June 2000 to June 2003, period representing the aftermath of dotcom crisis and therefore superior returns of minimum variance strategy are concentrated during extreme bearish periods. (Bali, Cakici, \& Whitelaw, 2011)further contest results of (Ang, Hodrick, Xing, \& Xhang, 2009) by arguing that inverted risk-return relationship is attributable to lottery like payoffs associated with high 
idiosyncratic volatility stocks and substantiate their results by developing variable MAX to proxy for the preference for lottery-like stocks. They try to establish that MAX is an independent variable and not a mere proxy for idiosyncratic volatility.

\section{Road Ahead}

\subsection{Critical review}

Risk anomaly has turned out to be one of the longest standing anomalies in the history of modern finance era. It seems to be a global phenomenon and has seriously challenged classic finance theory based on positive risk return relationship. While we have some studies highlighting positive risk-return relationship recently including (Martellini, 2008) and (Fu, 2009), both studies suffer from survivorship bias and look ahead bias respectively. Persistence of risk anomaly has led to researchers looking for explanations and there are enough and compelling economic as well as behavioral explanations to explain persistence of such anomaly. Some studies try to explain the anomaly away but that part of the evidence and weak and small at the moment. In closing, it looks like that while positive risk-return relation as prescribed by CAPM and MPT certainly holds true as asset class level but have come across severe scrutiny within the asset class, especially equity, where the evidence is growing for low volatility with higher expected return and vice versa.

The question here is that "Is this anomaly going to stay here forever or market learns over a period of time to phase it out?" The answer is as long as we have market frictions such as borrowing restrictions and short selling constraints, call option like compensation structure for portfolio managers that incentivizes them to pursue higher risk and reward them more for outperformance during positive markets only and benchmarking and minimizing tracking error as key performance measure, this is going to stay. Besides, emergence of behavioral finance has already established that investor behavior is far from rational both as well as institutional level and therefore preference for lottery, overconfidence, representativeness bias and limits of arbitrage are going to stay for a long, However, as professional investors learn about this, more and more investment strategies will target to benefit from this anomaly and in turn will make it less attractive. For sure, compensation structure of portfolio managers will undergo change to align it in such a manner that the portfolio managers don't have enough incentive for preferring high beta-low alpha stocks and will reward them for outperformance during down markets as well rather than only during up markets. Going forward, some of the changes may reduce the intensity of such anomaly in some of the markets but it seems to be far away.

\subsection{Scope for further research}

While there is plenty of work done in exploring and explaining (or explaining it away) risk anomaly, there is a scope for lot of work.

First, many strategies that have worked well on paper or theoretically have failed in practice due to execution problems due to market microstructure effects. Next phase of work may focus on evaluating potential of low volatility investment strategy vis-à-vis value weighted market portfolio in light of transaction cost, impact cost, taxes and such other microstructure issues. 
Second, is to provide more empirical evidence on some of the behavioral explanations. Except for preference for lottery where (Bali, Cakici, \& Whitelaw, 2011) have developed a clear and measurable variable to proxy for lottery-like stocks, other explanations are still more qualitative in nature.

Third, is to look at testing low volatility effect using implied volatility data from options markets rather than using historical volatility or using conditional volatility estimates such as EGARCH. The other area of work may be to look at equity mutual fund schemes rather than stocks and see whether risk anomaly can explain cross section of mutual funds' performance.

Forth, is some more work to provide clear linkage between positive risk-return relationship in cross section of asset returns and flatter or negative returns within the securities of given asset class.

\section{Conclusion}

We conclude that the risk anomaly is one of the strongest and longest standing anomalies of equity markets, which, it is going to stay here for a long time. It has posed significant challenge to classic finance theory. There are several compelling reasons that explain persistence of risk anomaly. One the one hand, we have economic and market friction based explanations, whereas on the one hand, there are behavioral explanations highlighting behavioral biases and irrational investors behavior causing risk anomaly. Yet another set of explanations attempt to challenge the very existence of risk anomaly and try to explain it away. In closing, it seems that while institutively appealing positive risk-return relationship is intact and capable of explaining cross section of returns of various asset classes, such relationship seem to be violated on a consistent basis across the securities within given asset class such as equity market friction that impose limits on arbitrage and irrational behavior on part of market participants that affect rational investment decision making lead to systematic overpricing of high volatility stocks and under pricing of low volatility stocks.

\section{References}

Ang, Andrew, Hodrick, Robert J., Xing, Yuhand, \& Zhang, Xiaoyan. (2006). The Cross Section of Volatility and Expected Return. Journal of Finance, 61(1), 259-299. http://dx.doi.org/10.1111/j.1540-6261.2006.00836.x

Ang, Hodrick, Xing, \& Y., Xhang. (2009). High Idiosyncratic Volatility and Low Returns: International and Further U.S. Evidence. Journal of Financial Economics, 91(1), 1-23. http://dx.doi.org/10.1016/j.jfineco.2007.12.005

Baker, Malcolm, Bradley, Brendan, \& Taliaferro, Ryan. (2013, January 23). The Low Risk Anomaly: A Decomposition into Micro and Macro Effects. Working Paper.

Baker, Malcolm, Bradley, Brendan, \& Wurgler, Jeffrey. (2011, January). Benchmarks as Limits to Arbitrage: Understanding the Low-Volatility Anomaly. Financial Analysts Journal, 67(1), 40-54. http://dx.doi.org/10.2469/faj.v67.n1.4 
Baker, Nardin, \& Haugen, Robert. (2012, April). Low Risk Stocks Outperform within All Observable Markets of the World. Journal of Portfolio Management, 17(3), 35-40. http://dx.doi.org/10.2139/ssrn.2055431

Bali, T. G., \& Cakici, N. (2008). Idiosyncratic Volatility and the Cross Section of Expected Returns. Journal of Financial and Quantitative Analysis, 43(1), 29-58. http://dx.doi.org/10.1017/S002210900000274X

Bali, Turan G., Cakici, Nusret, Whitelaw, \& Robert F. (2011). Maxing out: Stocks as lotteries and the cross-section of expected returns. Journal of Financial Economics, 99, 427-446. http://dx.doi.org/10.1016/j.jfineco.2010.08.014

Barber, Odean. (2008). All that Glitters: The Effect of Attention on the Buying Behaviour of Individual and Institutional Investors. Review of Financial Studies, 21(2), 785-818.http://dx.doi.org/10.1093/rfs/hhm079

Binsbergen, Jules H. Van, Brandt, Michael W., Koijen, \& Ralph S. J. (2008, August). Optimal Decentralized Investment Management. Journal of Finance, 63(4), 1849-1895. http://dx.doi.org/10.1111/j.1540-6261.2008.01376.x

Black, F. (1972, July). Capital Market Equilibrium with Restricted Borrowing. Journal of Business, 4(3), 444-455. http://dx.doi.org/10.1086/295472

Black, F. (1993, Fall). Beta and Return: Announcements of the 'Death of Beta" seem premature. The Journal of Portfolio Management, 20(1), 11-18. http://dx.doi.org/10.3905/jpm.1993.409462

Blitz, David C., Pang, Juan, \& Vliet, Pim Van. (2012). The Volatility Effect in Emerging Markets. Robeco Research Paper. http://dx.doi.org/10.2139/ssrn.2050863

Blitz, David C., \& Vliet, Pim Van. (2007). The Volatility Effect. The Journal of Portfolio Management, 34(Fall), 102-113. http://dx.doi.org/10.3905/jpm.2007.698039

Boyer, B., Mitton, T., \& Vorkink, K. (2010, January). Expected Idiosyncratic Skewness. Review of Financial Studies, 23(1). http://dx.doi.org/10.1093/rfs/hhp041

Carvalho, Raul, Leote de, Xiao, Lu, \& Pierre, Moulin. (2012). Demystifying Equity Risk-Based Strategies: A Simple Alpha plus Beta Description. Journal of Portfolio Management, 38(3).

Chan, L., Karceski, J., \& Lakonishok, J. (1999). Portfolio Optimisation: Forecasting Covariances and Choosing the Risk Model. Review of Financial Studies, 12, 937-974. http://dx.doi.org/10.1093/rfs/12.5.937

Choueifaty, Y., \& Coignard, Y. (2008). Toward Maximum Diversification. Journal of Portfolio Management, 35(1). http://dx.doi.org/10.3905/JPM.2008.35.1.40

Clarke, Roger, DeSilva, Harindra, Thorley, Steven. (2006b, December). Exploring the Risk Anomaly in the Equity Market. Economics and Portfolio Strategy. 
Clarke, Roger, DeSilva, Harindra, Thorley, Steven. (2006a). Minimum-Variance Portfolio in the U.S. Equity Market. The Journal of Portfolio Management, 33(Fall), 10-24. http://dx.doi.org/10.3905/jpm.2006.661366

Falkenstein. (1996). Preferences for Stock Characteristics as Revealed by Mutual Fund Portfolio Holdings. Journal of Finance, 51(1), 111-135. http://dx.doi.org/10.1111/j.1540-6261.1996.tb05204.x

Falkenstein. (2009). Risk and Return in General: Theory and Evidence. SSRN Working paper. http://dx.doi.org/10.2139/ssrn.1420356

Fama, E. F., \& French, K. R. (1992). The Cross-section of Expected Stock Returns. Journal of Finance, 47(2), 424-465. http://dx.doi.org/10.1111/j.1540-6261.1992.tb04398.x

Frazzini, A., \& Pedersen, L. H. (2014). Betting Against Beta. Journal of Financial Economics, 111(1), 1-25. http://dx.doi.org/10.1016/j.jfineco.2013.10.005

Fu, F. (2009). Idiosyncratic Risk and the Cross-Section of Expected Returns. Journal of Financial Economics, 91(1), 24-37. http://dx.doi.org/10.1016/j.jfineco.2008.02.003

Haugen, R. A., \& Baker, N. L. (1991). The Efficient Market Inefficiency of Capitalization-weighted Stock Portfolios. Journal of Portfolio Management, 17(3), 35-40. http://dx.doi.org/10.3905/jpm.1991.409335

Haugen, R. A., \& Heins, A. J. (1975, December). Risk and the Rate of Return on Financial Assets: Some Old Wine in New Bottles. Journal of Financial and Quantitative Analysis, 10(5), 775-784. http://dx.doi.org/10.2307/2330270

Haugen, Baker. (1996). Commonality in the Determinants of Expected Returns. Journal of Financial Economics, 41(3), 401-439. http://dx.doi.org/10.1016/0304-405X(95)00868-F

Hong, H., \& Sraer, D. A. (2012). Speculative Betas. NBER working paper. http://dx.doi.org/10.2139/ssrn.1967462

Jagannathan, R., \& Ma, T. (2003). Risk Reduction in large portfolios: Why imposing the wrong constraints helps. The Journal of Finance, 58(4), 1651-1684. http://dx.doi.org/10.1111/1540-6261.00580

Kahneman, D., \& Tversky, A. (1983, October). Extensional versus Intutive Reasoning: The conjunction Fallacy in Probability Judgment. Psychological Review, 90(4), 293-315.http://dx.doi.org/10.1037/0033-295X.90.4.293

Kahneman, D., \& Tversky, A. (1979, March). Prospect Theory: An Analysis of Decision under Risk. Econometrica, 47(2), 263-291. http://dx.doi.org/10.2307/1914185

Karceski, J. (2002, December). Returns-Chasing Behavior, Mutual Funds, and Beta's Death. Journal of Financial and Quantitative Analysis, 37(4), 559-594. http://dx.doi.org/10.2307/3595012 
Kumar, A. (2009, August). Who Gambles in the Stock Market? Journal of Finance, 64(4), 1889-1933. http://dx.doi.org/10.1111/j.1540-6261.2009.01483.x

Markowitz, H. (1952). Portfolio Selection. The Journal of Finance, 7(1), 77-91. http://dx.doi.org/10.1111/j.1540-6261.1952.tb01525.x

Martellini. (2008). Toward the Design of Better Equity Benchmarks: Rehabilitating the Tangency Portfolio from Modern Portfolio Theory. Journal of Portfolio Management, 34(4), 34-41. http://dx.doi.org/10.3905/jpm.2008.709978

Mitton, T., \& Vorkink, K. (2007, July). Equilibrium Underdiversification and the Preference for Skewness. Review of Financial Studies, 20(4), 1255-1288. http://dx.doi.org/10.1093/revfin/hhm011

Pettengill, G. N., Sundaram, S., \& Mathur, I. (1995, March). The conditional Relation between Beta and Return. Journal of Financial and Quantitative Analysis, 30(1), 101-116. http://dx.doi.org/10.2307/2331255

Poullaouec T. (2010). Things to Consider When Investing in Minimum Volatility Strategies. State Street Global Advisors Asset Allocation Research.

Schawartz, T. (2000). How to beat the S\&P 500 with portfolio optimization. Working paper, DePauls University.

Scherer, B. (2011). A Note on the Returns from Minimum Variance Investing. Journal of Empirical Finance, 18(4), 652-660. http://dx.doi.org/10.1016/j.jempfin.2011.06.001

Sharpe, W. (1964). Capital Asset Prices: A Theory of Market Equilibrium under Conditions of Risk. The Journal of Finance, 19(3), 425-442. http://dx.doi.org/10.1111/j.1540-6261.1964.tb02865.x

Soe, A. M. (2012, August 1). The Low Volatility Effect: A Comprehensive Look. S\&P DOW JONES Indices Paper. 